\title{
EFEKTIVITAS PEER GROUP DIABETES SELF CARE EDUCATION TERHADAP DIABETES SELF CARE ACTIVITIES PASIEN DM
}

\author{
Tramirta Trendi Iriani, Haryani*, Khudazi Aulawi \\ Program Studi Ilmu Keperawatan \\ Fakultas Kedokteran, Kesehatan Masyarakat, dan Keperawatan, Universitas Gadjah Mada \\ J1. Farmako, Sekip Utara, Yogyakarta, 55281, Indonesia \\ *)E-mail: haryani@ugm.ac.id
}

Dikirim: Juni 2016, diterbitkan: April 2017

\begin{abstract}
ABSTRAK
Latar belakang: Pasien diabetes melitus (DM) perlu mengontrol kadar glukosa darah dengan melakukan perawatan DM yang terdiri dari pengobatan, latihan, diet, dan edukasi. Peer group pada pasien DM dimungkinkan membantu perawatan DM. Tujuan penelitian: mengetahui efektivitas peer group diabetes self management education program (DSMEP) terhadap diabetes self-care activities DM tipe 2. Metode: Pre-eksperimental dengan rancangan one group pre-test-post-test design with control group. Pengambilan sampel menggunakan purposive sampling dari November-Maret 2013, dengan kriteria inklusi: DM tipe II dan $\geq 18$ tahun. Jumlah sampel masing-masing 13 pasien untuk kelompok intervensi dan kontrol. Kelompok perlakuan mendapatkan DSMEP, kelompok kontrol mendapatkan edukasi standar. Pretest diberikan sebelum intervensi, post test diberikan sebulan sesudah intervensi. Instrumen The Summary of Diabetes Self-Care Activities (validitas nilai r 0,361, Cronbach's Alpha 0,847) digunakan untuk mengukur aktivitas perawatan diri. Analisis data menggunakan $t$-test berpasangan dan tidak berpasangan. Hasil: Kebanyakan responden perempuan, lama pengobatan 10 tahun. Mayoritas pendidikan perguruan tinggi, suku Jawa, Islam, dan menikah. Terdapat perbedaan aktivitas perawatan diri sebelum dan sesudah dilakukan intervensi antara kelompok intervensi dan kontrol pada komponen pengobatan pasien $\mathrm{DM}(\mathrm{p}=0,005)$, tetapi tidak ada perbedaan yang signifikan pada komponen diet $(\mathrm{p}=0,077)$, olahraga $(\mathrm{p}=0,259)$, tes gula darah $(\mathrm{p}=0,058)$, dan perawat an kaki $(\mathrm{p}=0,309)$. Kesimpulan: Peer group diabetes self management education program (DSMEP) dapat meningkatkan kemampuan perawatan diri pasien DM tipe 2.
\end{abstract}

Kata Kunci: diabetes, peer group, self care, activities

\section{EFFECTIVENESS OF PEER GROUP-BASED DIABETES SELF-CARE EDUCATION ON DIABETES SELF-CARE ACTIVITIES IN DM PATIENTS}

\section{ABSTRACT}

Background: Diabetic patients need to control their blood glucose level through DM management consisting of medication, exercise, diet, and education. Peer group in DM patients may help DM treatment. Objective: To identify the effectiveness of peer group-based diabetes self-management education program (DSMEP) on diabetes self-care activities of type 2 DM. Methods: This study was pre-experimental with one group pre-test-post-test design with control group design. Samples were taken using purposive sampling from November to March 2013, with inclusion criteria of DM type II and $\geq 18$ years old. The sample size was 13 patients for each of the intervention and control group. The intervention group received $D S M E P$, while the control group received standard education. Pretest was given before the intervention and posttest was given a month after the intervention. The Summary Instrument of Diabetes Self-Care Activities (validity value $r>0.361$, Cronbach's Alpha $=0.847)$ was used to measure self-care activities. Data were analyzed using paired and unpaired t-test. Results: Most of the respondents were female and received more than 10 years of treatment. The majority of the respondents were tertiary educated, Javanese, Islamic, and married. There was a difference in self-care activity before and after intervention between the intervention and control groups in the component of DM patient treatment ( $p=0.005)$, but there 
was no significant difference in the components of dietary ( $p=0.077)$, exercise ( $p=0.259)$, blood sugar test $(p=0.058)$, and foot care ( $p=0.309)$. Conclusion: Peer group-based diabetes self-management education program (DSMEP) can improve self-care ability of type 2 diabetes patients.

Keywords: diabetes, peer group, self-care, activities

\section{LATAR BELAKANG}

World Health Organization (WHO) dan American Diabetes Association (ADA) mendefinisikan diabetes mellitus (DM) adalah suatu keadaan ketika tingkat glukosa plasma $126 \mathrm{mg} / \mathrm{dl}(7 \mathrm{mmol} / \mathrm{l})$ atau lebih (Eckardstein, 2004). Pada tahun 2004 WHO menyatakan bahwa 64 juta orang di dunia mengalami DM dan jumlah ini akan meningkat setiap tahun. Penderita DM diperkirakan akan mencapai 300 juta orang pada tahun 2030 (Tripathy, 2008).

International Diabetes Federation (IDF) memperkirakan prevalensi DM di Indonesia akan meningkat dari $5,1 \%$ pada tahun 2000 menjadi $6,3 \%$ pada tahun 2030 . Prevalensi DM di Indonesia diperkirakan mencapai 21.3 juta orang di tahun 2030 (Davey, 2002/2005).

DM merupakan penyakit kronis yang membutuhkan perawatan kompleks dan berkelanjutan, yang terdiri atas 4 pilar, yaitu pengobatan, latihan, diet, dan edukasi (Funnell \& Anderson, 2004). Kompleksitas dan keberlanjutan penanganan DM ini membutuhkan keterampilan pasien dalam mengintegrasikan penanganan DM secara mandiri dan berkelanjutan sehingga perlu dilakukan diabetes self management education (DSME) pada pasien diabetes (Smith et al., 2011). Dukungan dari teman sebaya (peer support/peer group) merupakan suatu sistem memberi dan menerima bantuan dengan prinsip rasa hormat, tanggung jawab bersama, dan kesepakatan bersama tentang hal-hal yang membantu (Gopichandran et al., 2012). Perilaku yang dilakukan oleh orang-orang dengan atau berisiko diabetes untuk mengelola penyakit tersebut dalam kehidupan sehari-hari disebut diabetes selfcare activities (Smith et al., 2011).

Berdasarkan teori yang sudah dijelaskan, peneliti tertarik untuk mengetahui efektivitas peer group diabetes self management education program (DSMEP) terhadap diabetes self-care activities pasien DM di RSUP Dr. Sardjito Yogyakarta. Tujuan penelitian ini adalah untuk mengetahui efektivitas peer group diabetes DSMEP terhadap diabetes self-care activities pasien DM di RSUP Dr. Sardjito Yogyakarta.

\section{METODE}

Penelitian ini menggunakan pendekatan kuantitatif dengan jenis pre-eksperimental dan rancangan yang digunakan one group pre-test-post-test design dengan comparison group. Penelitian ini dilaksanakan di Poliklinik Penyakit Dalam Rumah Sakit Umum Pusat (RSUP) Dr. Sardjito Yogyakarta pada bulan November 2012-Maret 2013. Populasi penelitian ini adalah penderita DM tipe 2. Sampel dalam penelitian pada kelompok kontrol berjumlah 13 orang dan perlakuan yang berjumlah 13 orang dan diambil dengan teknik purposive sampling.

Pengukuran aktivitas perawatan diri pasien diabetes menggunakan instrumen The Summary of Diabetes Self-Care Activities (SDSCA), yang merupakan instrumen yang dikembangkan oleh Toobert, Hampson, \& Glasgow (2000). Komponen SDSCA meliputi diet, olahraga, tes gula darah, perawatan kaki, pengobatan, dan frekuensi merokok serta rekomendasi perawatan diri. Di Indonesia kuesioner diabetes self-care activities (SDSCA) sudah dilakukan uji validitas dan 
reliabilitas oleh Ismonah (2008) di Rumah Sakit Panti Wilasa Citarum Semarang dengan hasil uji coba benar valid dengan nilai $r>0,361$ dan hasil uji reliabilitas dengan Cronbach's Alpha dengan hasil 0,847. Kuesioner ini kemudian dipakai di RSUP Dr. Sardjito di Poliklinik Penyakit Dalam.

Prosedur penelitian dimulai dari rekruimen pasien yang dilakukan di Poliklinik Endokrin RSUP Dr. Sarjito, sesuai dengan kirteria inklusi dan eksklusi yang ditetapkan. Calon responden kemudian diberikan penjelasan tentang jalannya penelitian dan informed consent. Sebelum intervensi dari rekam medis, dicatat BB dan TB untuk mengetahui $\mathrm{BMI}$, tekanan darah, gula darah puasa, gula darah 2 jam PP, level HbA1C, komplikasi dan jenis pengobatan DM. Kemudian responden diberikan kuesioner SDSCA. Kelompok intervensi mendapatkan pelatihan tentang DSME. Pelatihan diberikan di Laboratorium Program Studi IImu Keperawatan selama kurang lebih 2 jam. Materi diberikan oleh peneliti dan edukator DM RSUP Dr. Sardjito. Materi diberikan dalam bentuk ceramah dan demonstrasi.

Materi mencakup empat pilar penanganan DM yang meliputi apa itu DM dan pilar penanganan DM, perawatan kaki DM, demonstrasi senam kaki, demonstrasi cara penyuntikan insulin dan pengukuran gula darah mandiri. Isi materi berdasarkan rekomendasi dari IDF. Pemberian DSME ini dilakukan dalam 2 kali pertemuan. Dari 14 orang peserta yang diundang, yang datang 13 orang.

Setelah intervensi responden diberikan booklet yang berisi materi-materi DSM yang sudah diajarkan. Dilakukan group meeting satu kali di ruang tutorial PSIK FK UGM dan dilakukan dilakukan FGD selama kurang lebih 2 jam. Dalam FGD, masing-masing responden dapat membagi pengalaman mereka selama menerapkan DSM yang sudah diajarkan. Selain grup meeting formal, responden juga melakukan pertemuan secara informal dengan mengikuti kegiatan senam diabetes yang dilakukan setiap hari Rabu dan Jumat di RSUP Dr. Sardjito. Setelah satu bulan intervensi, responden kembali diberi kuesioner SDSCA. Data dianalisis dengan menggunakan $\mathrm{t}$ berpasangan dan $\mathrm{t}$ tidak berpasangan.

Penelitian ini telah mendapatkan izin laik etik dari Komite Etik Fakultas Kedokteran UGM. 


\section{HASIL}

Karakteristik Demografi Responden

Tabel 1. Karakteristik demografi responden pasien DM tipe 2

di Poliklinik Endokrin RSUP Dr. Sardjito Yogyakarta

bulan Desember 2012-Maret 2013 (n=26)

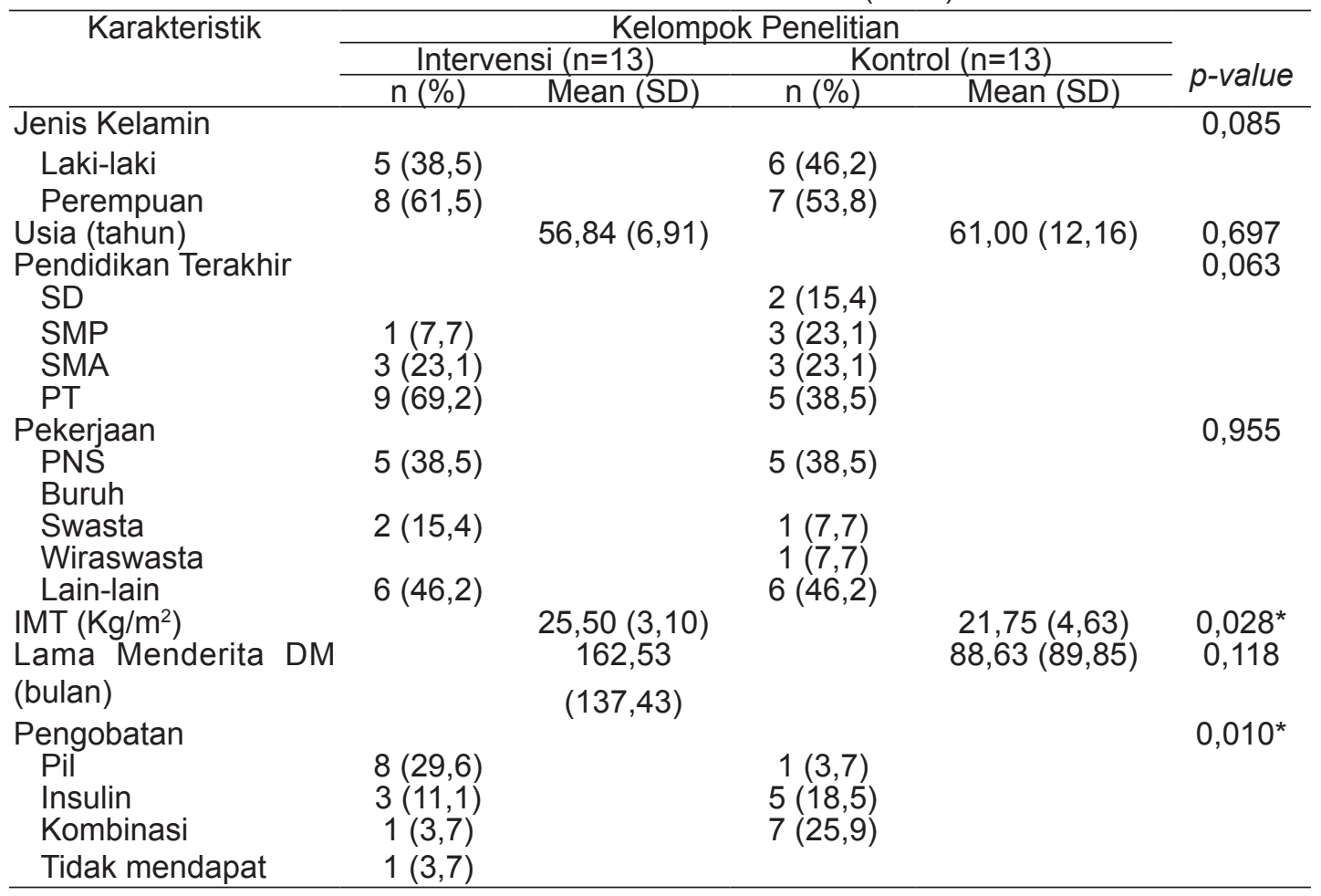

Berdasarkan Tabel 1 didapatkan hasil bahwa tidak terdapat perbedaan bermakna pada jenis kelamin, usia, pendidikan terakhir, pekerjaan, tinggi badan, dan lama menderita DM sehingga sampel dapat dikatakan homogen, tetapi IMT dan lama pengobatan terdapat perbedaan bermakna dan akan dijadikan bahan telaah dalam pembahasan.

Pengaruh Face to Face Peer Group
terhadap Diabetes Self Care Activity

Pengaruh peer group terhadap DSCA dapat diketahui dengan melakukan perbandingan rerata skor diet, olahraga, tes gula darah, perawatan kaki, pengobatan, kebiasaan merokok, dan rekomendasi perawatan diri pada kelompok intervensi dan kelompok kontrol. Perbedaan rerata skorskor tersebut pada kedua kelompok dianalisis secara bivariat dengan menggunakan independent samples t test. Hasil uji beda rerata skor diet kelompok intervensi dan kelompok kontrol ditunjukkan dengan tabel 2 sebagai berikut. 
Tabel 2. Pengaruh face to face pasien diabetes melitus tipe 2 kelompok intervensi dan kelompok kontrol di Poliklinik Endokrin

RSUP Dr. Sardjito Yogyakarta bulan Desember 2012-Maret 2013 (n=26)

\begin{tabular}{lccccc}
\multirow{2}{*}{ Subvariabel } & \multicolumn{2}{c}{ Kelompok Kontrol $(\mathrm{n}=13)$} & \multicolumn{2}{c}{ Kelompok Intervensi $(\mathrm{n}=13)$} & p-value \\
\cline { 2 - 5 } & Med (min-maks) & Mean (SD) & Med (min-maks) & Mean (SD) & \\
\hline Diet & $4,00(-10,00 ; 8,00)$ & $1,00(5,87)$ & $0.00(-17.00 ; 1,00)$ & $-2,07(4,74)$ & 0,077 \\
Olahraga & $1,00(-2,00 ; 8,00)$ & $2,30(3,04)$ & $0.00(-6.00 ; 6,00)$ & $0,07(2,72)$ & 0,259 \\
Tes Gula & $1,00(-5,00 ; 4,00)$ & $0,61(2,14)$ & $0.00(-2.00 ; 2,00)$ & $0,07(0,95)$ & 0,058 \\
Darah & & & & & \\
Pe raw wata n & $0,00(-15,00 ; 21,00)$ & $1,15(8,37)$ & $0.00(-7.00 ; 9,00)$ & $1,92(4,68)$ & 0,309 \\
Kaki & & & & & \\
Pengobatan & $0,00(-11,00 ; 6,00)$ & $0,30(5,02)$ & $7.00(-9.00 ; 16,00)$ & $5,07(9,34)$ & $0,005^{*}$ \\
\hline
\end{tabular}

Data ditampilkan dalam median karena kelompok intervensi di RSUP Dr. Sardjito data tidak terdistribusi normal (Tabel 2), Yogyakarta. Meskipun sebagian besar didapatkan hasil bahwa tidak ada perbedaan komponen diabetes self care activities yang bermakna antara aktivitas perawatan tidak berbeda bermakna antara kelompok diri pasien DM tipe 2 berupa diet, olahraga, intervensi dan kelompok kontrol, tetapi ada tes gula darah, dan perawatan kaki. Namun, kenaikan nilai rata-rata sebelum dan sesudah ada perbedaan bermakna pada subvariabel pemberian DSMEP, seperti tertera pada pengobatan antara kelompok kontrol dan gambar 1.

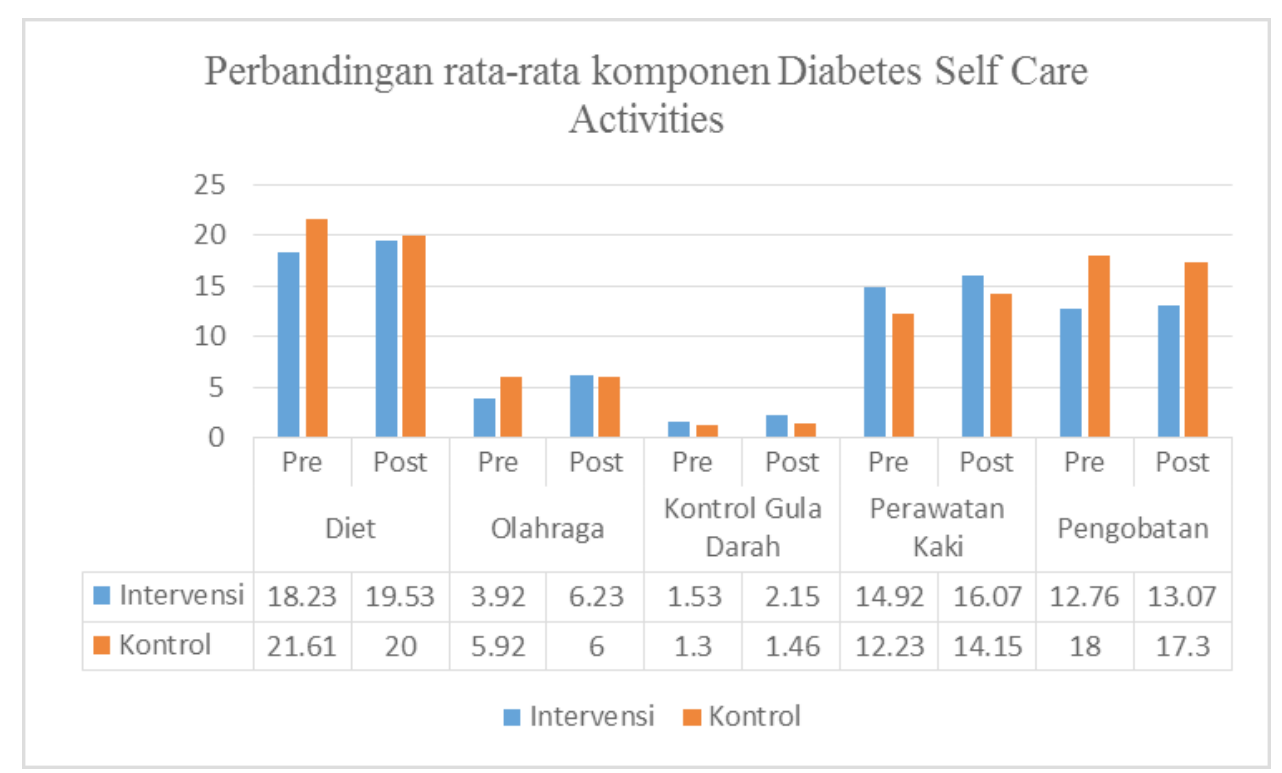

\section{Gambar 1. Perbandingan rata-rata komponen diabetes self care activities sebelum dan sesudah DSMEP pada kedua kelompok}

\section{DISKUSI}

Diet pada pasien DM tidak mengalami perbedaan yang signifikan, hal ini ditunjukkan pada Tabel 2 dengan ( $p=0,077$ ). Pada Gambar 1 diet pada kelompok intervensi mengalami

peningkatan 18,23 kali per minggu sebelum dan 20 kali seminggu sesudah. Sementara itu, pada kelompok kontrol terjadi penurunan, yaitu 21,61 kali seminggu pada pengambilan 
data pertama dan 19,53 kali seminggu pada pengambilan data kedua.

Hasil penelitian ini berbeda dari penelitian Copell et al. (2010) yang menyatakan bahwa terdapat perbedaan yang signifikan karena pasien diberikan perlakuan berupa saran diet (sesuai dengan rekomendasi gizi dari European Association for the Study of Diabetes (Coppell et al., 2010).

Pengetahuan pasien DM tentang diet sebelum dan sesudah dilakukan intervensi sudah baik sehingga dengan adanya pendidikan tentang diet, pasien dengan DM lebih bisa menerima dan menjalankan diet tersebut untuk menangani penyakit DM agar memperoleh kualitas hidup yang baik (Sutiawati, Jafar, \& Yustini, 2013). Dengan demikian, pemberian intervensi face to face tidak memberikan dampak yang cukup baik.

Frekuensi olahraga yang dilakukan juga tidak berbeda pada kedua kelompok $(p=0,259)$. Pada Gambar 1 frekuensi olahraga kelompok intervensi mengalami peningkatan yaitu sebanyak 3,92 kali selama seminggu dan setelah diberikan intervensi face to face frekuensi olahraga mengalami peningkatan, yaitu 6,23 kali seminggu. Frekuensi olahraga pasien DM kelompok kontrol juga mengalami peningkatan, yaitu 5,92 kali seminggu pada saat pengambilan data pertama dan meningkat menjadi 6 kali seminggu pada pengambilan data kedua. Hal ini menunjukkan bahwa intervensi face to face sangat baik dilakukan karena pasien semakin rutin untuk melakukan senam. Pasien dalam kedua kelompok mengikuti program olahraga yang terstruktur yang bertujuan untuk mengontrol kadar glikemik dalam tubuh (Sigal et al., 2006).

Pasien DM setelah dilakukan intervensi face to face semakin sering melakukan olahraga berupa senam diabetes yang rutin. Hal tersebut berarti semakin rajin seseorang melakukan olahraga untuk mengeluarkan kalori, gula darah pasien DM tersebut dapat terkontrol dengan baik (Colberg, Hernandez, \& Fatima, 2013).

Pemeriksaan gula darah pada kelompok intervensi dan kelompok kontrol juga tidak mengalami perbedaan yang signifikan $(p=0,058)$. Pasien DM pada kedua kelompok selalu melakukan pemeriksaan gula darah sebulan sekali di rumah sakit secara rutin sehingga pemberian intervensi face to face tidak memberikan dampak yang cukup besar.

Walau begitu, pada Gambar 1 dapat dilihat bahwa tes gula darah pada kelompok intervensi, yaitu 1,53 kali selama seminggu dan setelah diberikan intervensi face to face frekuensi tes gula darah mengalami peningkatan, yaitu 2,15 kali seminggu. Pada kelompok kontrol juga terjadi peningkatan, yaitu 1,3 kali seminggu pada saat pengambilan data pertama dan meningkat menjadi 1,46 kali seminggu.

Semua pasien DM dengan HbA1C $\geq 8$ diberi pendidikan face to face untuk diajari cara mengukur gula darah sehingga pemantauan gula darah pasien DM lebih terstruktur pada status glikemik (Aghili et al., 2012). Pemantauan perawatan kaki yang kurang pada pasien DM $(p=0,628)$. Hal ini disebabkan pasien belum tahu tentang cara merawat kaki yang benar agar terhindar dari komplikasi (Somroo et al., 2011). Dengan demikian, pemberian intervensi face to face tidak memberikan hasil yang cukup baik.

Pasien DM pada kelompok intervensi dan kontrol belum memahami tentang perawatan kaki sehingga tidak terdapat perbedaan yang signifikan $(p=0,309)$. Pasien DM tersebut beranggapan bahwa perawatan kaki hanya dilakukan untuk pasien DM yang mengalami luka pada bagian kaki dan bukan untuk pasien yang tidak mempunyai masalah kaki. Akan tetapi, pada Gambar 1 didapatkan hasil bahwa perawatan kaki pada kelompok intervensi mengalami peningkatan, yaitu sebanyak 
14,92 kali selama seminggu dan setelah diberikan intervensi face to face frekuensi perawatan kaki mengalami peningkatan yaitu 16,07 kali seminggu. Perawatan kaki pasien DM kelompok kontrol selama seminggu juga mengalami peningkatan yaitu 12,23 kali seminggu pada saat pengambilan data pertama dan meningkat menjadi 14,15 kali seminggu. Hal ini disebabkan pasien DM selalu menjaga kebersihan kakinya dengan cara mencuci kaki (Al-Wahbi, 2010).

Pemantauan perawatan kaki yang kurang pada pasien DM $(p=0,628)$. Hal ini disebabkan karena pasien belum tahu tentang cara merawat kaki yang benar agar terhindar dari komplikasi (Somroo et al., 2011). Dengan demikian, pemberian intervensi face to face tidak memberikan hasil yang cukup baik. Pendidikan tentang perawatan kaki yang intensif pada pasien DM harus diajarkan untuk membantu dalam mencegah penyakit kaki diabetik (Viswanathan et al., 2005).

Terdapat perbedaan yang signifikan pada pengobatan berupa meminum pil atau penyuntikan insulin yang dilakukan oleh kelompok intervensi dan kontrol $(p=0,005)$. Pada Gambar 1 didapatkan hasil bahwa ratarata pasien DM melakukan pengobatan pada kelompok intervensi mengalami peningkatan, yaitu sebanyak 12,76 kali selama seminggu dan setelah diberikan intervensi face to face frekuensi perawatan kaki mengalami peningkatan, yaitu 13,07 kali seminggu. Sementara itu, rata-rata pengobatan pasien DM kelompok kontrol selama seminggu mengalami penurunan, yaitu 18 kali seminggu pada saat pengambilan data pertama dan meningkat menjadi 17,3 kali seminggu. Hal ini berarti intervensi face to face memberikan hasil yang baik pada pasien DM tipe 2 di RSUP Dr. Sardjito Yogyakarta. Keteraturan menjalankan pengobatan DM bertujuan untuk menstabilkan kadar gula darah agar tetap normal di dalam tubuh.
Penyuntikan insulin dalam tubuh juga memiliki tujuan untuk menstabilkan kadar gula darah. Apabila kadar gula di dalam darah tinggi, sekresi insulin akan meningkat. Sebaliknya, apabila kadar gula darah rendah, maka sekresi insulin juga akan menurun. Dalam keadaan normal, kadar gula darah di bawah $80 \mathrm{mg} / \mathrm{dl}$ akan menyebabkan sekresi insulin menjadi sangat rendah (Direktorat Bina Farmasi dan Klinik, 2005). Pasien DM yang hanya diberikan obat pada awal pengobatan dengan $\mathrm{HbA} 1 \mathrm{C}>7$ tidak efektif dan belum mampu menurunkan kadar $\mathrm{HbA} 1 \mathrm{C}<7$ sehingga pemberian insulin sangat dengan $\mathrm{HbA} 1 \mathrm{C}>7$ tidak efektif dan belum mampu menurunkan kadar $\mathrm{HbA} 1 \mathrm{C}<7$ sehingga pemberian insulin sangat penting. Insulin lebih efektif apabila diberikan di awal pengobatan pada pasien dengan kadar HbA1C >7 dan dikombinasikan dengan obat-obat DM untuk dapat mengontrol kadar glukosa menjadi lebih baik (Barag, 2011).

\section{SIMPULAN}

Hasil penelitian menunjukkan terdapat perbedaan yang signifikan pada pengobatan pasien $(p=0,005)$ setelah dilakukan face to face peer group DSMEP dengan sebelum dilakukan face to face peer group DSMEP terhadap peningkatan diabetes self care activities pada pasien penderita DM tipe 2 pada kelompok intervensi dan kelompok kontrol di RSUP Dr. Sardjito Yogyakarta.

\section{DAFTAR PUSTAKA}

Aghili, R., Khamseh, M.E., Malek, M., Yarahmadi, S., dan Farshchi, A. (2012). Structured self monitoring of blood glucose in Iranian people with type 2 diabetes: A cost consequence analysis. DARU Journal of Pharmaceutical Science, 20(1): 32.

Al-Wahbi, A.M. (2010). Impact of a diabetic foot care education program on lower limb amputation rate. Dovepress: 
Vascular Health and Risk Management, 6: 923-934.

Barag, S.H. (2011). Insulin therapy for management of type 2 diabetes mellitus: Strategies for initiation and longterm patient adherence. Journal Am Osteopath Association, Supplement 5, 111(7): S13-S16.

Colberg R.S., Hernandez, J.M., Fatima, F. (2013). Diabetes Care; 36(10): e177-e177.

Coppell, K.J., Kataoka, M., Williams, S. M., Chisholm, A. W., Vorgers, S. M., \& Mann, J.I. (2010). Nutritional intervention in patients with type 2 diabetes who are hyperglycaemic despite optimised drug treatment - lifestyle over and above drugs in diabetes (LOADD) study: Randomised controlled trial. British Medical Journal, 341: c3337.

Davey, P. (2005). At a glance medicine. (Alih bahasa: Anissa Rahmalia). Jakarta: Erlangga. (Buku asli diterbitkan 2002).

Direktorat Bina Farmasi dan Klinik. (2005). Pharmaceutical care untuk penyakit diabetes mellitus. Jakarta: Departemen Kesehatan RI.

Eckardstein, A.V. (2004). Atherosclerosis: Diet and drugs. Germany: Springer.

Funnell, M.M. \& Anderson, R.M. (2004). Empowerment and self-management of diabetes. Clinical Diabetes, 22(3): 123-127.

Gopichandran, V., Lydon, S., Angel, M.K., Manayalil, B.P., Blessy, K.R., Alex, R.G., Kumaran, V., \& Balraj, V. (2012). Diabetes self-care activities: A community-based survey in urban Southern India. The National Medical Journal of India, 25(1): 14-17.

Ismonah. (2008). Analisis faktor-faktor yang berhubungan dengan self care management pasien diabetes melitus dalam konteks asuhan keperawatan di RS Panti Wilasa Citarum Semarang (Tesis). Universitas Indonesia, Jakarta, Indonesia.

Sigal, R. J., Kenny, G. P., Wasserman, D. H., Scepa, C. C., \& White, R. D. (2006). Physical activity/exercise and type 2 diabetes. Diabetes Care, 29(6): 14331438

Smith, S. M., Paul, G., Kelly, A., Whitford, D. L., O'Shea, E., \& O'Dowd, T. (2011). Peer support for patients with type 2 diabetes: Cluster randomised controlled trial. British Medical Journal (BMJ), 342: d715 Somroo, J.A., Hashmi, A., Iqbal, Z., dan Ghori, A. (2011). Diabetic foot care - A public health problem. Journal Medicine, 12(2): 109-114

Sutiawati, M., Jafar, N., \& Yustini. (2013). Pengaruh edukasi gizi terhadap pengetahuan, pola makan dan kadar glukosa darah pasien diabetes melitus tipe 2 RSUD Lanto' Dg Pasewang Jeneponto". Media Gizi Masyarakat Indonesia, 2(2): 78-84.

Toobert, D. J., Hampson, S. E., \& Glasgow, R.E. 2000. The summary of diabetes self-care activities measure: Results from 7 studies and a revised scale. Diabetes Care, 23(7), 943-950.

Tripathy, B.B. (2008). Textbook of diabetes mellitus. Volume I. New Delhi: Jaypee Brothers Medical Publisher.

Viswanathan, V., Madhavan, S., Rajasekar, S., Chamukuttan, S., dan Ambady, R. (2005). Amputation prevention initiative in South India: Positive impact of foot care education. Diabetes Care, 28(5), 1019-1021. 